\title{
A EMERGÊNCIA DA NOÇÃO DE NOVAS TECNOLOGIAS NO CENTRO PARA PESQUISA E INOVAÇÃO EDUCACIONAL DA OCDE
}

\author{
THE EMERGENCE OF THE NOTION OF NEW TECHNOLOGIES AT OECD CENTRE \\ FOR EDUCATIONAL RESEARCH AND INNOVATION
}

\section{LA EMERGENCIA DE LA NOCIÓN DE NUEVAS TECNOLOGÍAS EN EL CENTRO PARA LA INVESTIGACIÓN E INNOVACIÓN EDUCATIVAS DE LA OCDE}

Fernando Cesar Sossai ${ }^{1}$

\section{RESUMO}

Como a noção de novas tecnologias emergiu no âmbito do Centro para Pesquisa e Inovação Educacional (CERI) da Organização para a Cooperação e Desenvolvimento Econômico (OCDE)? Quais aproximações foram construídas entre essa noção e a educação? Essas são as questões que animam este escrito. O texto está organizado em duas partes. Na primeira, além de apresentar uma caracterização das instâncias de gestão da OCDE, discuto como se deu a articulação entre educação e tecnologias durante o processo de constituição do CERI (1968-1971). Em seguida, por meio da interpretação de fontes coletadas na OECD Library \& Archives (Paris), analiso como a noção de novas tecnologias historicamente emergiu no CERI de maneira associada a perspectivas de futuro sobre trabalho, emprego e políticas internacionais de educação.

PALAVRAS-CHAVE: OCDE. Tecnologia e educação. Políticas de educação.

\begin{abstract}
How did the notion of new technologies emerge in the Centre for Educational Research and Innovation (CERI) of Organisation for Economic Co-operation and Development (OECD)? Which approximations did organisation build between this notion and education? These are the questions that animate this article. The article is organised in two parts. First of all, more than just present a characterization of the OECD's administration bodies, I discuss how the articulation between education and technologies took place during the CERI constitution process (1968-1971). After that, through the interpretation of sources researched in the OECD Library \& Archives (Paris), I analyse how the notion of new technologies historically emerged at CERI in articulation with its future perspectives about work, employment and international education policies.
\end{abstract}

KEYWORDS: OECD. Technologies and education. Education policies.

\footnotetext{
${ }^{1}$ Doutor em Educação - Universidade do Estado de Santa Catarina (UDESC). Florianópolis, SC - Brasil. Professor Adjunto II - Universidade da Região de Joinville (UNIVILLE). Joinville, SC - Brasil.

E-mail: fernandosossai@gmail.com

Submetido em: 18/03/2020 - Aceito em: 13/07/2020
}

(C) ETD-Educação Temática Digital $\quad$ Campinas, SP $\quad$ v.23 $\quad$ n.4 $\quad$ p. 963-981 $\quad$ out./dez. 2021 


\section{RESUMEN}

¿Cómo surgió la noción de nuevas tecnologías en el interior del Centro para la Investigación e Innovación Educativas (CERI) de la Organización para la Cooperación y el Desarrollo Económicos (OCDE)? ¿Cuáles aproximaciones se han construido en la OCDE entre esta noción, la enseñanza y la educación? Esas son las preguntas que impulsan este artículo. El artículo fue organizado en dos apartados. En el primero, además de presentar una caracterización de los órganos de gestión de la OCDE, examino como se produjo la articulación entre educación y tecnologías en el transcurso del proceso de constitución del CERI (1968-1971). En continuidad, a través de la interpretación de fuentes investigadas en la OECD Library \& Archives (Paris), analizo como la noción de nuevas tecnologías ha emergido en el CERI en articulación con perspectivas de futuro sobre trabajo, empleo y políticas internacionales de educación.

PALAVRAS CLAVE: OCDE. Tecnologías y educación. Políticas educativas.

\section{$* * *$}

\section{INTRODUÇÃO}

Se comparada a outros organismos internacionais, como o Grupo Banco Mundial e a Organização das Nações Unidas para a Educação, a Ciência e a Cultura (Unesco), é possível afirmar que a Organização para a Cooperação e Desenvolvimento Econômico (OCDE) recebeu pouca atenção de pesquisadores brasileiros dedicados ao campo da educação. Assim, este artigo procura contribuir nessa direção.

Atualmente, a OCDE é constituída de uma coalização de 37 Estados que se associaram à entidade por meio da ratificação da Convention on the Organisation for Economic Cooperation and Development (OECD), realizada em Paris, em 14 de dezembro de 1960 (OECD, $1960)^{2}$. Além deles, outros cinco países integram a instituição na qualidade de parceiroschave (África do Sul, Brasil, China, Indonésia e Índia). Em seu conjunto, os 37 Estados que dão base formal à organização perfazem a população de 1,175 bilhão de habitantes e 61,3\% do produto interno bruto (PIB) mundial (US\$ 38,282 trilhões).

Do ponto de vista jurídico, a OCDE é mundialmente reconhecida como uma organização internacional (OI) de escopo e abrangência globais. De acordo com o jurista Mario Bettati (1998, p. 33), organizações como a OCDE são entes com "personalidade jurídica internacional que Ihe confere a qualidade de sujeito do Direito Internacional Público". Tal personalidade é efeito de um tratado que materializa a voluntariedade de diferentes Estados nacionais de participarem de uma mesma entidade de atuação multilateral. Em termos educacionais, conforme apontado por Stephen Ball (2014), instituições como a OCDE funcionam como um espaço de convergência de políticas globais de educação, prestando-se ao trabalho de alinhamento tanto de projetos do presente quanto de intenções de futuros internacionalizados em educação.

\footnotetext{
${ }^{2} \mathrm{~A}$ listagem completa dos países que integram a entidade encontra-se Disponível em: https://www.oecd.org/about/members-and-partners/. Acesso em: 12 jan. 2020.
}

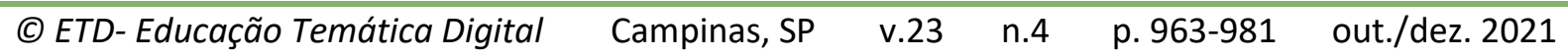


No que concerne ao seu mandato, a OCDE (2016) define-se como uma organização internacional voltada à "promoção de políticas que melhorem a economia e o bem-estar social das pessoas em todo mundo". Nessa direção, entende como o fio condutor de seu trabalho o "compromisso comum com as economias de mercado apoiadas por instituições democráticas e centradas no bem-estar de todos os cidadãos" (OECD, 2016). Assim, a instituição projeta-se como um "fórum no qual os governos podem trabalhar juntos para compartilhar experiências e buscar soluções para problemas comuns" (OECD, 2016).

Desde que completou 50 anos, em 2011, a organização passou a atuar tomando como referência um conjunto de propósitos mais específicos, enfocando a ajuda a governos nacionais, sobretudo no que diz respeito à produção, coleta, análise e disponibilização de dados estatísticos; à tradução multilíngue de publicações, especialmente de estudos econômicos, educacionais e energéticos; à oferta de consultoria para agentes e/ou órgãos públicos; à revisão e avaliação de políticas; e à elaboração de documentos de políticas (BARROSO, 2003 e OECD, 2017a). Com base em tais práticas, por um lado, a OCDE busca minimizar o fato de não possuir plena autoridade dentro das fronteiras de seus Estados associados (poder de mando jurídico, financeiro ou político). Por outro, ela tem procurado se interpor como uma espécie de agência global produtora, reguladora e difusora de políticas, principalmente em educação (MAUÉS, 2011).

Ao longo de sua trajetória, a OCDE dedicou-se intensamente à elaboração e ao desenvolvimento de políticas educacionais de alcance transnacional, muitas delas relacionadas à produção, análise e disponibilização de indicadores, historicamente figurando como uma espécie de expert organisation. A produção exacerbada de indicadores e estatísticas educacionais cumpriu e ainda cumpre papel singular no modus operandi da OCDE, uma vez que ela "depende do desenvolvimento de bons argumentos para ter influência

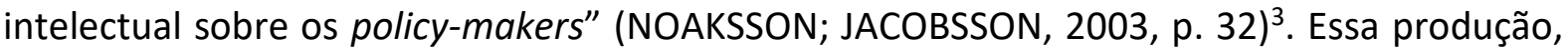
segundo Freitas (2012, p. 383), contribuiu, em termos históricos, tanto para a construção de um pensamento e de uma agenda reformista da educação quanto para a conformação de uma espécie de teoria da responsabilização, cuja principal característica é a defesa de posturas meritocráticas e gerencialistas dos sistemas nacionais de educação, com "ênfase nos processos de gerenciamento da força de trabalho" das pessoas e calcadas em uma racionalidade técnica que valoriza testes padronizados (standards) a serem aplicados em larga escala por agências e agentes vinculados à organização ${ }^{4}$.

\footnotetext{
${ }^{3}$ Doravante, todas as traduções deste artigo são livres e elaboradas pelo autor.

${ }^{4}$ Nesse sentido, podem ser compreendidos dois programas permanentes da organização: o OECD Teaching and Learning International Survey (TALIS) e o OECD's Programme for International Student Assessment (PISA). Uma interessante análise desses programas pode ser encontrada no trabalho de Da Costa e Afonso (2009).
} 
$\mathrm{Na}$ esteira dessa perspectiva, este escrito persegue duas questões que animam uma à outra: como a noção de novas tecnologias emergiu no âmbito do Centro para Pesquisa e Inovação Educacional (CERI) da OCDE, particularmente nos domínios de seu Comitê de Educação e Conselho de Administração? Ao fazer nascer essa noção, quais aproximações foram construídas entre educação e novas tecnologias? Com base nessas indagações, o artigo foi organizado em duas partes. Na primeira, além de apresentar a caracterização das principais instâncias de gestão da OCDE, discuto como se deu a articulação entre educação e tecnologias durante o processo de constituição do CERI e de seu respectivo Comitê de Educação (1968-1971). Em seguida, analiso como a noção de novas tecnologias historicamente emergiu no interior do centro de maneira associada tanto a perspectivas de futuro sobre trabalho e emprego quanto a visagens de futuras políticas internacionais de educação.

Em termos metodológicos, além de um diálogo teórico-conceitual com a literatura pertinente, ao longo do texto faço uso de um conjunto de fontes primárias coletadas no ano de 2016 na sede da OECD Library Archives, em Paris (França). Em sua maioria, essas fontes foram originalmente elaboradas nos idiomas oficiais da organização (inglês e francês) e correspondem aos denominados OECD draft documents, isto é, documentos institucionais ainda não validados em todas as instâncias da entidade e, portanto, raramente tornados públicos. Em seu contexto de arquivamento, tais documentos são classificados como "de acesso restrito", devendo circular apenas entre pessoas, setores e agências envolvidos com suas matérias. Em números, foram pesquisados 276 arquivos digitais, perfazendo 30 gigabytes de dados, abrangendo o período compreendido entre 1960 e $1992^{5}$.

Ademais, não é prolixo dizer que este artigo visa contribuir para investigações interessadas em discutir como organizações similares à OCDE se constituem enquanto estruturas artificiais de uma rede global de diálogos político-econômicos em torno de matérias de grande relevância e impacto na vida de pessoas que vivem em diferentes regiões do planeta (nomeadamente, políticas de educação e tecnologia supostamente voltadas ao desenvolvimento econômico e à melhoria da sociedade).

\footnotetext{
${ }^{5}$ Tal conjunto documental foi coletado no contexto da tese de doutorado intitulada "Pelos gabinetes da OCDE: a construção de consensos sobre educação e tecnologia (1960-1992)", desenvolvida entre 2013 e 2017 no Programa de Pós-graduação em Educação da Universidade do Estado de Santa Catarina.
}

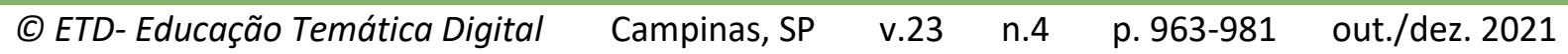




\section{A OCDE, O CERI E O COMITÊ DE EDUCAÇÃO}

Assim como à época de sua constituição, no início dos anos 1960, a estrutura de gestão da OCDE continua sendo operada por três principais instâncias institucionais: o Conselho, o Secretariado e os Comitês. A Figura 1 apresenta informações sistematizadas acerca de como se articulam essas instâncias de gestão.

Figura 1 - Diagrama alusivo às instâncias de gestão da Organização para a Cooperação e Desenvolvimento Econômico (OECD)

\section{Quem dirige o trabalho da OCDE? Conselho}

Supervisão e direção estratégica

Representantes de países-membros e da Comissão Europeia; presidido pelo secretário-geral; decisões são tomadas por consenso

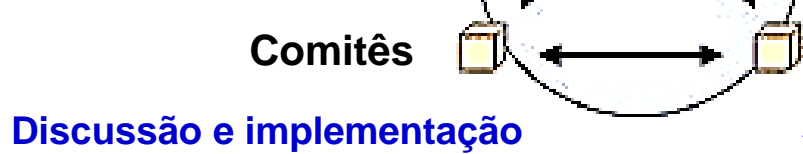

Discussão e implementação

Representantes dos países-membros e de países com status de observador trabalham com 0 Secretariado da OCDE em questões específicas

\section{Secretariado} Análises e propostas

Secretário-geral

Secretários-gerais adjuntos

Diretorias

Fonte: elaborado pelo autor com base em OECD (2017b).

O Conselho da OCDE é composto de um representante de cada Estado membro permanente da organização e um representante da Comissão Europeia. Sob a presidência do secretário-geral, os integrantes do Conselho reúnem-se periodicamente e suas "decisões são tomadas por consenso" (OECD, 2017b). Uma vez por ano, também é realizada a reunião do Conselho com a presença dos ministros de países integrantes do quadro permanente da instituição. Os propósitos dessa reunião são "debater questões-chave e definir as prioridades para os trabalhos da OCDE" (OECD, 2017b).

O Secretariado da OCDE encontra-se sediado em Paris e possui cerca de "2.500 funcionários" (OECD, 2017b). Sua equipe é constituída de "economistas, advogados, cientistas e outros profissionais" (OECD, 2017b) contratados para prestar assessoria técnica em assuntos de interesse da organização. O órgão tem as funções de apoiar as "atividades dos comitês" e executar os trabalhos definidos como prioritários durante a reunião do

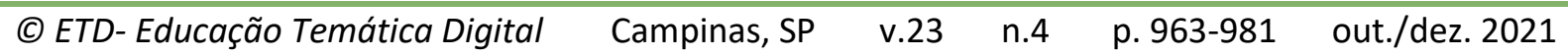


Conselho. Além do secretário-geral, o Secretariado da organização é assistido por um chefe de staff e por "um ou mais secretários-gerais adjuntos", que buscam fortalecer a "ligação entre as delegações internacionais e o próprio Secretariado" (OECD, 2017b) ${ }^{6}$.

Os comitês da instituição são integrados por "representantes dos 37 países-membros da OCDE" (OECD, 2017b) organizados em grupos especializados. A expectativa da organização é que os comitês consigam "aprofundar ideias e analisar o progresso em áreas políticas específicas, como economia, comércio, ciência, emprego, educação ou mercados financeiros" (OECD, 2017b). De acordo com a entidade:

Há cerca de 250 comitês, grupos de trabalho e grupos de experts. Quase 40 mil funcionários seniores de governos nacionais comparecem anualmente às reuniões dos comitês da OCDE para requerer, examinar e contribuir para o trabalho desenvolvido pelo Secretariado da organização. Uma vez que esses funcionários retornam aos seus países, eles passam a ter acesso on-line aos documentos e podem trocar informações por meio de uma rede especial (OECD, 2017b).

Um dos comitês mais destacados da organização é o de Educação. Tal comitê encontra-se vinculado ao Centro para Pesquisa e Inovação Educacional da OCDE, internacionalmente conhecido pela sigla CERI. Ao longo da história da organização, tal órgão vem se dedicando à coleta, análise, sistematização e publicação de indicadores e estatísticas em educação, assim como à promoção e coordenação de ações no marco dos programas TALIS, PISA e Innovative Teaching for Effective Learning (ITEL) ${ }^{7}$.

Em termos históricos, o CERI e o seu Comitê de Educação foram constituídos entre 1968 e 1971, com a "ajuda de uma subvenção da Fundação Ford, que foi posteriormente complementada por uma outra subvenção do Grupo Shell" (PAPADOPOULOS, 1994, p. 64). À época, a criação do centro e do comitê pretendia trazer para o interior da OCDE um "campo emergente de pesquisa e análise" em educação: a "inovação educacional" (BENGTSSON, 2008 , p. 1). Especificamente em 1968, a concepção do centro foi acompanhada pela preocupação de ele ser "supervisionado por um conselho diretivo" - o Conselho de Administração -, integrado por "personalidades independentes e nomeadas pelo secretáriogeral da OCDE", as quais deveriam ser escolhidas levando em conta suas "competências individuais" (OECD, 1971, p. 4) ${ }^{8}$. De fato, tal arranjo permitia à cúpula da OCDE supervisionar de forma mais direta e precisa os trabalhos do CERI, além de garantir ao secretário-geral a

\footnotetext{
${ }^{6}$ Desde 2006, o secretário-geral da OCDE é o mexicano Angel Gurría. Em seu gabinete, ele é apoiado por Gabriela Ramos (chefe de staff), assim como por Masamichi Kono, Jeffrey Schlagenhauf, Ludger Schuknecht e Ulrik Vestergaard Knudsen, que ocupam as funções de secretários-gerais adjuntos (OECD, 2017b).

${ }^{7}$ Como a mundialmente conhecida Education at a Glance, uma publicação em série editada pela OCDE desde 1992, que compila e apresenta "dados sobre a infraestrutura, as finanças e o desempenho dos sistemas educacionais nos países da organização e em outras economias parceiras" (OECD, 2019).

${ }^{8}$ Nesse período, o secretário-geral da OCDE era o dinamarquês Thorkil Kristensen, cujo mandato se iniciou em setembro de 1961 e finalizou em setembro de 1969.
}

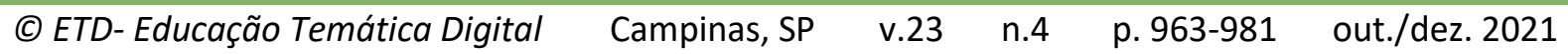


prerrogativa de demover pessoas que obstaculizassem projetos de interesse da organização e/ou de um de seus Estados-membros.

Também, o centro e seu Comitê de Educação teriam surgido para qualificar os debates educacionais da organização, avançando-os para além de meras discussões de resultados alcançados por meio de pesquisas quantitativas. Segundo o entendimento de Jarl Bengtsson (2008), um dos diretores mais conhecidos da história do CERI, na esfera da economia da educação, as abordagens quantitativas de fenômenos educativos já tinham cumprido papel importante na história da entidade, pois vinham gerando dados que serviam de base para a oferta de consultoria política aos Estados integrantes da organização ${ }^{9}$. O surgimento do CERI buscava ir além disso e impulsionar outros tipos de serviços no interior da OCDE. Nesse sentido, foram concebidos os seguintes objetivos para o centro:

Promover e apoiar o desenvolvimento de atividades de investigação no domínio da educação e, se for o caso, realizar essas atividades onde for apropriado;

Promover e apoiar experiências piloto a fim de introduzir e testar inovações nos sistemas educativos;

Promover o desenvolvimento da cooperação entre os países-membros no campo da pesquisa educacional e inovação (OECD, 1971, p. 4).

No marco desses objetivos, não é equivocado dizer que as inovações educacionais eventualmente criadas sob os auspícios do CERI e de seu Comitê de Educação já viriam ao mundo dotadas de um signo de distinção. Isto é, as inovações fabricadas no interior do centro apareceriam ao mundo certificadas pela própria OCDE, ostentando um selo de qualidade que as destacariam no embrionário mercado das inovações, decorrente da expansão da pesquisa científica e tecnológica envolvendo universidades e empresas. Ao que parece, a melhor estratégia competitiva para os players desse mercado seria a busca pela validação institucional de uma inovação educacional, muito mais do que pela validação de uma ideia, de um método ou de um processo inovador.

Seja como for, no diálogo com aqueles três objetivos, no CERI e seu Comitê de Educação, o cruzamento entre educação e tecnologias foi efetuado sob a promessa de que tais instâncias poderiam formular proposições políticas que, ao serem implementadas, garantiriam o progresso econômico-social dos Estados parte da organização. Para tanto, cumpriria aos países da OCDE transformar de maneira radical a educação oferecida em suas escolas, até mesmo reposicionando seus sistemas nacionais de educação ante as

\footnotetext{
${ }^{9}$ Além de diretor do CERI (1991-1999), entre 1971 e 2002, Bengtsson ocupou diversos cargos importantes do staff da OCDE. Em 1999, ganhou notoriedade global por ser um dos idealizadores do PISA. Antes do seu falecimento, em 2013, encerrou sua carreira na Danish School of Education, Universidade de Aarhus, e na Board of Pascal International Observatory.
} 
contingências de um tempo premido por mudanças tecnológicas que reivindicavam uma nova compreensão acerca dos meios e dos fins da educação nacional.

No contexto de constituição do CERI, tal entendimento evidencia-se em numerosos discursos proferidos pelo primeiro diretor do centro, James R. Grass. De sua ótica, inúmeros argumentos poderiam ser mobilizados para justificar a inserção de tecnologias em contextos educacionais diversificados, mas, sobretudo, o fato de "inovações tecnológicas", mais precisamente o computador, estarem se espalhando "pela sociedade com uma velocidade assustadora" (GRASS, 1971, p. 7). Para o diretor, a transposição dessa perspectiva na educação escolar exigiria a concepção e a oferta de "cursos de reconhecimento" para que adultos e crianças construíssem familiaridade com máquinas que, até então, lhes eram desconhecidas. Segundo ele, somente assim seria possível às crianças em idade escolar "entender o ambiente tecnológico ao seu redor", bem como aos adultos abandonar seus "medos exagerados" em relação ao uso de computadores (GRASS, 1971, p. 7).

Destarte, não resta a menor dúvida de que, entre 1968 e 1971, a constituição do CERI e de seu Comitê de Educação contribuíram tanto para difundir uma crença positiva no que se refere à colagem educação e tecnologias quanto para que, ano após ano, essa relação se tornasse um ponto de pauta da agenda educacional da OCDE.

Além das fontes que analisei neste item, corroboram essa afirmação muitas outras que coletei no acervo da OECD Library \& Archives. Contudo a análise do conjunto das fontes indica que seria apenas no transcurso dos anos 1980 que a organização conseguiria construir e irradiar internacionalmente os consensos que desejava quando o assunto era a aproximação entre educação e tecnologias. Tais consensos tiveram de esperar a formulação de outra noção no interior do CERI e de seu Comitê de Educação, a noção de novas tecnologias ${ }^{10}$.

\footnotetext{
${ }^{10}$ Embora o objetivo deste artigo não seja apresentar um debate conceitual a respeito da contemporânea noção de novas tecnologias, vale a pena citar alguns trabalhos. Sobre a noção de novas tecnologias na educação, ver Sossai (2011). Concernente à relação currículo, políticas educacionais e novas tecnologias na educação, ver Sossai, Mendes e Pacheco (2010) e Sossai e Mendes (2013). Acerca da expressão novas tecnologias e suas conexões com a cultura digital, ver Sossai (2019). No que tange ao cruzamento entre novas tecnologias, história da comunicação e a invenção de aparelhos analógicos, elétricos, eletrônicos e digitais (séculos XV ao XX), ver Briggs e Burke (2006). No tocante à expressão novas tecnologias e sua relação com experiências de tempo em educação, ver Sossai e Mendes (2016).
}

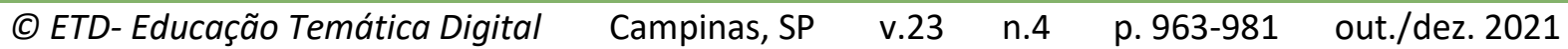




\section{A NOÇÃO DE NOVAS TECNOLOGIAS NO ÂMBITO DO COMITÊ DE EDUCAÇÃO E DO CONSELHO DE ADMINISTRAÇÃO DO CERI}

No transcurso dos anos 1980, no interior da OCDE, o aparecimento da noção de novas tecnologias - inicialmente sem o adjetivo educacionais ou o adjunto adnominal de informação - remetia-se à necessidade de os países da organização incrementarem sua infraestrutura de telecomunicações, intensificando formas de comunicação que resultassem em ganhos econômicos.

Se investigada no marco dos interesses educacionais da instituição, a emergência dessa noção remonta ao começo da década de 1980. Numa Proposta de Trabalho de 7 de maio de 1980, cuja execução se previa para o ano subsequente, o Comitê de Educação ${ }^{11}$ e o Conselho de Administração do CERI assumiram o compromisso de "aconselhar o Secretariado da OCDE" quanto à "implementação das atividades" de três áreas estratégicas: "(i) educação, emprego e economia", "(ii) educação e ajustes estruturais" e "(iii) estratégias de ensino e formação profissional" (OECD, 1980, p. 2) ${ }^{12}$. Ao tratar do item ii, o documento registrou que, "em 1981, o Comitê de Educação considerará os resultados de um trabalho exploratório do Secretariado acerca das implicações educacionais do desenvolvimento industrial e tecnológico de longo prazo". Para dar conta desse trabalho, o staff do Conselho de Educação do CERI sugeriu a "configuração de um grupo de experts para aconselhar o Secretariado sobre a preparação de um relatório prospectivo acerca do assunto" (OECD, 1980, p. 3). A ideia era "criar um grupo de trabalho ad hoc sobre educação profissional e formação" que, ao longo de um ano, ficaria responsável por entregar ao Secretariado um relatório contendo os "princípios que poderiam guiar o desenvolvimento, a longo prazo, de políticas integrais de ensino e formação profissional, em relação ao desenvolvimento econômico e ao uso de novas tecnologias" (OECD, 1980, p. 4).

Quase um ano depois, em 7 de abril de 1981, o assunto foi continuado em um brief paper $^{13}$ elaborado pelos funcionários do gabinete do Secretariado da organização. Com o título Desenvolvimento da educação para mudanças nas condições sociais, econômicas $e$ tecnológicas, o documento era muito mais complexo do que aquela proposta de trabalho e explicava que o Comitê de Educação havia solicitado o brief paper para que servisse de "base para a discussão da variedade de problemas que poderiam ser tomados como áreas

\footnotetext{
${ }^{11}$ Quatro integrantes compunham o Comitê de Educação do CERI: “Robert Leestma (presidente, Estados Unidos da América), Anders Arfwedson (vice-presidente, Suécia), Klaus Roelofs (vice-presidente, Alemanha) e Daniele Sette (vice-presidente, Itália)" (OECD, 1981c, p. 349).

${ }^{12}$ À época, compunham o Secretariado da OCDE os franceses Gerard Eldin (janeiro/1970 a março/1980) e Paul Lemerle (março/1980 a abril/1985) e os estadunidenses Charles G. Wootton (janeiro/1974 a julho/1980) e Jacob M. Myerson (setembro/1980 a setembro/1998).

13 Documento elaborado sob a supervisão do gabinete do Secretariado com o objetivo de pautar e/ou fundamentar debates sobre assuntos estratégicos ao futuro da OCDE e de seus Estados-membros.
} 
prioritárias [...] de seu futuro programa de trabalho", especialmente áreas como o "planejamento e o desenvolvimento da educação para mudanças nas condições sociais, econômicas e tecnológicas" dos países da OCDE (OECD, 1981b, p. 1).

Além de enfatizar a necessidade de valorizar as opiniões expressadas pelo "grupo de estudo de experts" convocados a assistir os trabalhos do secretariado, do Comitê de Educação e do CERI, o brief paper sugeria que fossem instigadas discussões sobre "futuras políticas educacionais" sensíveis às maneiras pelas quais a educação "deveria influenciar o desenvolvimento social em geral" (OECD, 1981b, p. 5). Segundo o documento, tais políticas precisariam prever o "inter-relacionamento entre educação e desenvolvimento social em geral", limitando-se a propor um "número significativo e manejável de pontos de vista" ao redor de "quatro aspectos do desenvolvimento [...]: economia, tecnologia, vida sociopolítica, a vida cultural do indivíduo e a comunidade" (OECD, 1981b, p. 6). Em um item específico, o documento não se furtou à tarefa de conceituar o termo tecnologia nem, em seguida, de explicitar seu entendimento sobre a noção de novas tecnologias:

Tecnologia pode ser definida como a aplicação de conhecimento científico para a produção de bens e à performance de serviços. Isso pode ser corporificado em equipamentos, materiais, métodos de trabalho ou habilidades humanas. [...] As tecnologias, recentemente, têm entrado numa nova fase, que é significativamente diferente da fase passada em virtude do seu escopo e de suas aplicações. Novas tecnologias, principalmente baseadas em eletrônicos, energias atômica e bioquímica têm sido desenvolvidas em anos recentes e estão começando a ser utilizadas mais amplamente (OECD, 1981b, p. 12).

Ao relacionar essas discussões ao conjunto das 15 páginas do brief paper, é possível perceber o esforço da OCDE em construir a expressão novas tecnologias ao redor da maquinaria eletrônica que rapidamente se espalhava entre as sociedades congraçadas pela organização. De acordo com esse documento, o uso de tecnologias eletrônicas estava "começando a gerar dramáticas mudanças na vida social, na produção, no trabalho e na aprendizagem" (OECD, 1981b, p. 12). Na perspectiva do Secretariado da OCDE, a disseminação do uso de novas tecnologias na sociedade exigia a apreciação de quatro questões básicas para o futuro. A primeira dizia respeito ao advento das novas tecnologias e seus efeitos sobre o emprego. Nesse âmbito, o documento destacava que, a curto prazo, o uso de novas tecnologias poderia sim levar ao "desemprego e à obsolescência de capital fixo", assim como à "diminuição de redes de emprego, de educação e de formação" (OECD, 1981b, p. 13). Nessa direção, o brief paper ainda registrava que, inevitavelmente, "alguns membros da força de trabalho, incluindo aqueles com certas habilidades e os não qualificados, poderão não ser mais necessários e suas rendas reais declinarão" (OECD, 1981b, p. 13). Mesmo diante desse cenário, o documento era categórico: "De outra parte, novas tecnologiais têm de ser produzidas" (OECD, 1981b, p. 13).

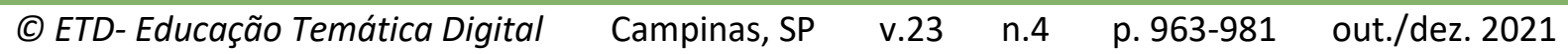


Nos domínios do Comitê de Educação também se chamava a atenção dos Estados parte da OCDE para outra questão considerada fundamental: "Se e como a educação pode ajudar a sociedade a tomar o controle da tecnologia, quer em suas raízes científicas, quer em suas utilizações, em favor de orientar a evolução da vida econômica e social para as direções desejadas" (OECD, 1981b, p. 13). Nas entrelinhas, o que estava sendo dito era que a "futura performance econômica dos diversos países da OCDE" seria "governada pelas suas habilidades de competir em tecnologia" e pela sua capacidade de formular uma "política de desenvolvimento industrial baseada numa escolha deliberada de alta tecnologia" (OECD, 1981b, p. 13).

Uma terceira situação afligia parte do staff educacional da OCDE. Como mediar as novas e imprevisíveis demandas educacionais advindas da proliferação de novas tecnologias na sociedade? Ante contextos laborais diversificados, quais seriam as melhores estratégias de formação de trabalhadores para o uso dessas tecnologias? Oferecer aos seus associados respostas satisfatórias para essas perguntas não era nada simples. Afinal, na perspectiva da organização, independentemente de qual fosse a "rede de efeitos das novas tecnologias sobre o nível de emprego", estava "visivelmente claro que tais efeitos" sempre gerariam "novas necessidades em educação e formação" (OECD, 1981b, p. 14). A bem da verdade é que essas necessidades implicavam maiores despesas, pois requeriam "reformas na educação e na formação", bem como a expansão das "oportunidades de atualização ou mesmo a aprendizagem contínua em serviço" (OECD, 1981b, p. 14). De fato, o brief paper continha apenas uma resposta evasiva àquelas perguntas: "Em princípio, se as novas tecnologias são eficientes para a melhoria da produção e da produtividade, elas gerarão os recursos para educação e formação" (OECD, 1981b, p. 14).

Para além disso, no interior da OCDE, havia ainda mais uma questão a ser abordada em relação à expansão global das novas tecnologias: "A capacidade de gerar progresso científico e tecnológico" (OECD, 1981b, p. 15). Segundo a entidade, esse assunto era de "particular relevância para políticas de educação superior" e, mais precisamente, para impulsionar o desenvolvimento de "pesquisas em universidades e outras instituições de educação superior" (OECD, 1981b, p. 15). Ao que tudo indica, a preocupação era que a parca "articulação entre essas duas esferas" - universidades/instituições de ensino superior e expansão global de novas tecnologias - poderia "afetar [...] o bem-estar de instituições acadêmicas e sua habilidade de performar o papel de repositórios de expertise" e de provedoras de "recursos de mão de obra" para a "indústria e outras instituições econômicas e sociais" (OECD, 1981b, p. 15).

Aprofundando aspectos educacionais considerados singulares às novas tecnologias, 0 referido documento ressaltava três pontos a serem levados em conta no cruzamento de tais tecnologias com a educação: i) a combinação das "tecnologias eletrônicas" ao papel do

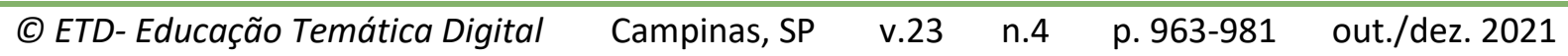


professor na busca pela aceleração da aprendizagem e à melhoria do desempenho dos "alunos lentos"; ii) a possibilidade de o "processo de aprendizagem [...] se alongar em espaço e tempo para atender às necessidades de populações de áreas isoladas"; iii) a capacidade dos sistemas computacionais de lidarem com uma "imanejável quantidade de informações", o que "torna possível modificar a forma sob a qual o conhecimento é apresentado e faz com que novos níveis de análises e entendimentos sejam possíveis" (OECD, 1981b, p. 15).

Quase de imediato, as recomendações daquele brief paper foram transpostas para outro documento: a Minuta do Programa de Trabalho para o ano de 1982, elaborada pela equipe do CERI da OCDE. Em 13 de abril de 1981 (seis dias depois de o gabinete do Secretariado expedir aquele brief paper), uma primeira versão do programa sugeria estudos sobre as novas tecnologias da microeletrônica e o desenvolvimento educacional. Isso era imperioso, pois, à época, a microeletrônica estava se anunciando como uma grande área de tecnologias do futuro, podendo influenciar significativamente o desenvolvimento industrial dos países da OCDE. Segundo o documento, por estar voltada à fabricação de "produtos cada vez mais miniaturizados, individualizados e baratos", a microeletrônica poderia ter "implicações abrangentes para a indústria, o emprego e as condições de trabalho, assim como para a educação e outros serviços públicos" (OECD, 1981a, p. 16). Para além disso, ela poderia gerar "mudanças dramáticas no processo de produção e no controle e disseminação do crescente volume de conhecimento e informação que as sociedades modernas geram" (OECD, 1981a, p. 16).

Diante do avanço exponencial das novas tecnologias, a OCDE defendia que a educação deveria assumir um mandato planificado nos seus Estados parte. Com o oferecimento de formação, a educação possuía "papel estratégico na preparação de um crescente número de especialistas [...], aparelhando os trabalhadores com habilidades e qualificações necessárias" ao mercado. Além disso, seria também a educação que assumiria a "responsabilidade de preparar a população para viver com essas novas tecnologias", ensinando-as a "controlá-las [...] em sua vida diária" (OECD, 1981a, p. 17).

Defender o caráter seminal da educação ante o aumento da produção e o uso de novas tecnologias ainda não respondia a uma complexa interrogação dos Estados-membros da organização: como a educação poderia assumir o seu papel estratégico, em nível operativo e concreto, num tempo em que se começava a acreditar que as experimentações com a microeletrônica poderiam ser um grande legado do presente ao futuro? Ao abordar a articulação entre educação e tecnologias, o Comitê de Educação sugeriu o redesign da formação de professores e do currículo escolar dos países-membros da organização. Nos termos daquele documento, no começo dos anos 1980, não havia mais como negar que as novas tecnologias estavam gerando forte "impacto sobre os conteúdos e a organização do currículo, sobre os métodos de ensino, para a melhoria do acesso à informação, e sobre a

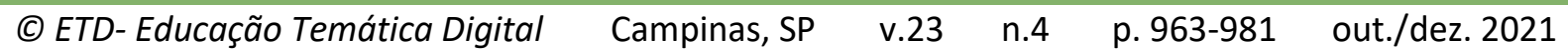


gestão e organização da escola" (OECD, 1981a, p. 17). O contexto exigia enfrentar "novas necessidades para a formação de professores, em vista da posição estratégica que os professores ocuparão para tornar o sistema educacional hábil a alcançar a revolução tecnológica que está ao seu redor" (OECD, 1981a, p. 17).

Nesse sentido, o Comitê de Educação e o Conselho de Administração do CERI propuseram como Programa de Trabalho para o ano de 1982 os assuntos indicados a seguir:

(a) As implicações das novas tecnologias para o conteúdo e os métodos de ensino; (b) como softwares apropriados poderiam ser adequadamente desenvolvidos para propósitos educacionais, para cumprir a promessa, e evitar o perigo, de avanços da indústria baseada em hardware. Isso poderia ser prosseguido por um estudo do papel da educação e da formação na preparação de indivíduos para o uso dessas tecnologias em vários aspectos da vida social. Um plano detalhado para um projeto de dois anos sobre as linhas anteriores deverá ser submetido ao Conselho de Administração em novembro de 1981, em reunião (OECD, 1981a, p. 17).

Ao investigar a documentação gerada pelo Comitê de Educação e pelo Conselho de Administração do CERI, percebem-se estratégias de influência e de regulação soft corporificadas em amarrações de bastidores para que tais pontos fossem levados adiante nos anos posteriores. No Relatório de Progresso Global do Comitê de Educação e do Conselho de Administração do CERI referente ao ano de 1981 (tornado público em 18 de março de 1982), foram listadas seis "áreas prioritárias ao futuro trabalho de resposta aos novos problemas do desenvolvimento educacional" dos países da OCDE, em virtude da "mudança das condições socioeconômicas dos anos 1980" (OECD, 1982b, p. 2). No topo da lista, incluiu-se a necessidade de os governos se atentarem à "interação entre educação e outros setores da política" com capacidade de influenciar a "transformação social, econômica e das condições tecnológicas" dos Estados irmanados na organização (OECD, 1982b, p. 2). Nas dobras desse documento, é possível vislumbrar esforços por parte da OCDE no sentido de fabricar um epíteto mais poderoso para a articulação entre educação e novas tecnologias. Refiro-me a uma breve passagem daquele relatório em que podemos identificar os interesses da entidade em relação a esse assunto:

Educação e Novas Tecnologias de Informação (CERI) - Um trabalho preparatório foi desenvolvido durante o ano [1981] para esse novo projeto, incluindo um encontro de experts, o qual levou a propostas detalhadas para futuros trabalhos submetidos e aprovados pelo Conselho de Administração do CERI na reunião de novembro de 1981 (OECD, 1982b, p. 9).

Três semanas depois, o Comitê de Educação e o Conselho de Administração do CERI produziram um novo documento no qual reafirmavam seus compromissos institucionais para com a matéria. Distribuída aos diversos setores da OCDE, em 7 de abril de 1982, a Minuta do Programa de Trabalho para o ano de 1983 apresentava informações sobre acordos construídos nos bastidores do comitê, bem como detalhes acerca das bases em que estavam 
apoiadas certas reflexões a respeito do devir das novas tecnologias na educação, nomeadamente a "natureza e as várias formas de uso das novas tecnologias na educação", a "amplitude de sua aplicação" nas instituições educacionais e o "nível de compromisso de políticas públicas nessa área" formuladas e desenvolvidas pelos países-membros da organização (OECD, 1982a, p. 16).

No princípio da década de 1980, no âmago do Comitê de Educação da OCDE, considerava-se fundamental a realização de um estudo detalhado acerca de políticas e tendências globais de produção e uso de novas tecnologias na educação. À época, a ambição da organização era conhecer o "impacto da introdução das novas tecnologias [...] sobre o funcionamento de instituições educacionais e sobre o processo educacional em si" (OECD, 1982a, p. 16). Entre outras, a expectativa era desenvolver uma pesquisa a respeito de como o papel do professor estava sendo afetado pela expansão dessas tecnologias, bem como identificar que "contribuições as novas tecnologias poderiam oferecer [...] para a aprendizagem de grupos desfavorecidos, tanto entre a população escolar quanto entre os adultos" (OECD, 1982a, p. 16). Tal investigação também se comprometia a analisar experiências positivas de utilização das novas tecnologias na educação escolar oferecida por alguns dos sistemas educativos de países integrantes da organização. A proposta apensada àquela minuta destacava a necessidade, em "pequeno número", de "estudos de caso, cuidadosamente selecionados [...], baseados na experiência de instituições e sistemas" que tinham acumulado uma "tradição razoavelmente bem estabelecida na aplicação de novas tecnologias" (OECD, 1982a, p. 16). Nesse âmbito, seriam "elaboradas análises iniciais acerca do que as escolas" poderiam fazer "para ajudar indivíduos no entendimento crítico e na utilização de pervasivas novas tecnologias", cada vez mais acessíveis em "sociedades de intensa informação" (OECD, 1982a, p. 16). Nas próprias palavras da organização, "as experiências dos países-membros [...] com as novas tecnologias e a introdução das ciências da informação no currículo serão analisadas e avaliadas" (OECD, 1982a, p. 16).

Ademais, naquele documento, as equipes do Comitê de Educação e do Conselho de Administração do CERI também assumiram o compromisso de apresentar "os resultados do trabalho" sob a forma de um "relatório geral para discussão na Conferência Internacional sobre Novas Tecnologias, Informação e suas Implicações Educacionais", que iria ocorrer "no outono de 1983" (OECD, 1982a, p. 16). A conferência era considerada um lugar privilegiado à socialização das conclusões do estudo, sobretudo porque nela seriam elaboradas as propostas de pesquisa em educação e novas tecnologias para os anos de 1984 e 1985 . Embora eventos como esse gerassem um enorme volume de discussões, para além do que foi citado até aqui, a coleta de dados na sede da OECD Library \& Archives resultou em apenas mais uma fonte representativa dos bastidores da referida conferência. Na Minuta do Programa de Trabalho do Comitê de Educação e do Conselho de Administração do CERI para o ano de 1986, elaborada em 3 de maio de 1985, há algumas informações atinentes à realização daquela

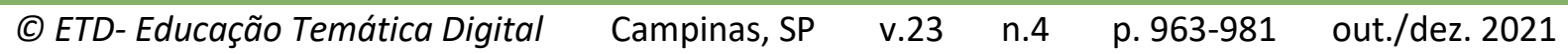


conferência, não no outono de 1983, mas em julho de 1984. O exame do documento revela que, nas esferas mais poderosas da OCDE, havia intensa movimentação de bastidores para fomentar, influenciar e regular projetos e ideias sobre como educação e novas tecnologias poderiam ser aproximadas. Conforme exposto na minuta:

\begin{abstract}
Projeto 1: Educação e Novas Tecnologias de Informação - A primeira fase desse projeto, que culminou na Conferência Internacional de julho de 1984, enfocava a coleta e análise de informações sobre políticas, práticas e pesquisas relacionadas à introdução de novas tecnologias na educação, bem como em avaliar o possível impacto dessas tecnologias sobre o funcionamento geral do sistema educacional. Baseado nas conclusões e recomendações da conferência, o Conselho de Administração do CERI, em sua sessão de fevereiro de 1985, apreciou as propostas para a próxima fase do trabalho, tendo em conta a importância que foi atribuída ao futuro trabalho nessa área no comunicado de novembro de 1984, do Comitê de ministros de Estado da OCDE (OECD, 1985, p. 9, grifos meu).
\end{abstract}

No transcurso da pesquisa documental na OECD Library \& Archives não tive acesso ao comunicado mencionado na citação. São essenciais futuras investigações sobre as reverberações da conferência entre os Estados-membros da organização. Seja como for, a Minuta do Programa de Trabalho do Comitê de Educação e do Conselho de Administração do CERI para 1986 também propunha pesquisas que, efetivamente, culminassem na produção de dados sobre os avanços auferidos pelas aproximações que já tinham sido construídas entre educação e novas tecnologias. Nessa direção, o compromisso do Comitê de Educação e do Conselho de Administração do CERI era trabalhar, em "colaboração com as autoridades dos países-membros da OCDE e com a ajuda de experts", na preparação de "relatórios gerais" a respeito do "potencial das novas tecnologias de informação para o aprimoramento do processo de ensino e aprendizagem" (OECD, 1985, p. 9). A juízo da entidade, os relatórios eram "documentos de fundamentação para a discussão de representantes nacionais e experts" e deveriam ser utilizados para preparar o terreno da "conferência internacional sobre as aplicações educacionais das novas tecnologias de informação: avaliação de experiências e futuros projetos", que ocorreria em 1986 (OECD, 1985, p. 9). A crença da organização parecia ser a de que esses relatórios não apenas influenciariam as discussões da conferência, mas também regulariam o seu fluxo analítico.

Como se nota, a fabricação da expressão novas tecnologias foi uma operação artificial no interior da OCDE. Por um lado, nela foram embutidos desejos de futuro atinentes à melhoria das condições socioeconômicas dos Estados-membros da organização. Por outro, procurou-se colar a ela o adjunto adnominal de informação. Por dentro, o conjunto da expressão novas tecnologias de informação trazia em seu bojo promessas de futuros internacionais em educação. Assim, durante os anos 1980, a aproximação entre educação e novas tecnologias (de informação) evidenciava um trabalho astuto por parte da OCDE: aos seus Estados parte, ela ofertava profecias sobre como seria o futuro educacional do planeta; ao emergente mercado global de tecnologias microeletrônicas/computacionais, ela prometia

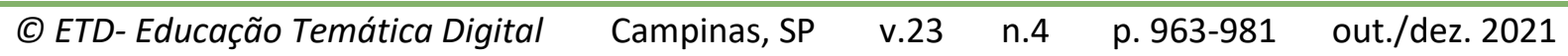


um horizonte infindável de escolas consumidoras de produtos informáticos - bastava apenas que os governos nacionais tomassem suas decisões levando em conta as recomendações da organização -; às sociedades que tomassem como referência as perspectivas defendidas pela entidade, ela oferecia o conforto de que estava fazendo algo em favor das futuras gerações: preparando-as para lidar com as desconhecidas novas tecnologias.

\section{CONSIDERAÇÕES FINAIS}

Ao longo de sua história, a OCDE buscou se consolidar como uma autoridade científica global e se posicionar como uma instituição habilitada a predizer futuros educacionais internacionais. Nessa busca, não poupou esforços para "esboçar um modelo de educação universal" adaptável "a esse futuro (imaginário), a que muitas vezes [denominou de] era da informação" (BEECH, 2009, p. 36). Ao dar forma a essa ambição, a entidade fabricou numerosas propostas de educação, muitas das quais transpareciam forte preocupação com a modelização de sistemas educativos (procurando estimulá-los ao atendimento de supostas contingências advindas de "mudanças tecnológicas permanentes" que impactavam a economia, a ciência e o acelerado desenvolvimento tecnológico nos anos 1980). A ideia da OCDE parecia ser não apenas "projetar soluções para os problemas educativos" do seu próprio presente, mas também antecipar e preparar os caminhos para tornar mínimos problemas políticos, econômicos e sociais que poderiam irromper em anos vindouros (BEECH, 2009, p. 36-37). Assim, é factível que a instituição imaginava à educação papel mais complexo do que o de uma mera ferramenta para a realização desse tipo de trabalho. A educação era, pois, o próprio futuro no presente.

Dessa perspectiva, a noção de novas tecnologias foi construída com a ativa participação de experts em educação, sendo energizada por debates educacionais mediados pela OCDE no transcurso dos anos 1980. Tal noção também foi fabricada em meio a discussões educacionais que transpassavam os poderosos fóruns da organização (nomeadamente, o Secretariado da instituição, o Comitê de Educação e o Conselho de Administração do CERI).

Renunciando ao entendimento segundo o qual a noção de novas tecnologias tomou de assalto o campo da educação (avançando tão somente de fora para dentro: dos estudos da microeletrônica para a educação), creio ser mais profícua a defesa de que a noção de novas tecnologias foi sendo histórica e intencionalmente construída por meio de interações entre os diversos domínios em que a OCDE possuía interesse, influência e algum poder de interferência/regulação (eventos e pesquisas científicas, opinião de experts, discursos políticos, governos, agências públicas, empresas privadas, escolas, entre outros).

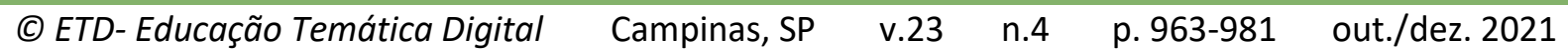


Foi no transcurso da década de 1980 que a organização empreendeu esforços contínuos e sistemáticos para conformar suas redes de influência quando o assunto em pauta era a aproximação entre educação e novas tecnologias. O saldo dessa conformação parece ter sido a construção de desejados consensos internacionais a respeito de como seria viável a articulação entre educação e tecnologias computacionais. Nesse âmbito, um último passo ainda teria de ser dado pela OCDE: disseminar esses consensos não apenas entre os seus Estados associados, mas em todos os cantos do planeta. Esse foi o empreendimento levado a cabo pela organização nos anos 1990 e que parece durar até o tempo presente.

\section{REFERÊNCIAS}

BALL, Stephen J. Educação Global S.A.: novas redes de políticas e o imaginário neoliberal. Tradução de Janete Bridon. Ponta Grossa: UEPG, 2014.

BARROSO, João. Organização e regulação dos Ensinos Básico e Secundário, em Portugal: sentidos de uma evolução. Educação e sociedade, v. 24, p. 63-92, 2003.

BEECH, Jason. A internacionalização das políticas educativas na América Latina. Currículo sem fronteiras, v. 9, n.2, p. 32-50, 2009.

BENGTSSON, Jarl. OECD's Centre for Educational Research and Innovation - 1968 to 2008. Paris: OECD, 2008.

BETTATI, Mario. Création et personnalité juridique des organisations internationales. In : DUPUY, Rene-Jean (Org.). Manuel sur les organizations internationales. Boston: Brill-Nijhoff \& Leiden University, 1998. p. 33-60.

BRIGGS, Asa; BURKE, Peter. Uma história social da mídia: de Gutenberg à internet. 2. ed. Rio de Janeiro: Jorge Zahar, 2006.

DA COSTA, Estela; AFONSO, Natércio. Os instrumentos de regulação baseados no conhecimento: o caso do Programme for International Student Assessment (PISA). Educação e sociedade, v. 30, p. 1037-1055, 2009.

FREITAS, Luiz C. Os reformadores empresariais da educação: da desmoralização do magistério à destruição do sistema público de educação. Educação e sociedade, v. 33, p. 379-404, 2012.

GRASS, James R. Preface. In: OECD. CERI. Seminar on computer sciences in secondary education: March $9^{\text {th }} / 14^{\text {th }}, 1970$ [Report]. Paris: OECD, 1971.

MAUÉS, Olgaíses C. A política da OCDE para a educação e a formação docente. A nova regulação? Educação, v. 34, p. 75-85, 2011.

MENDES, Geovana M. L.; SOSSAI, Fernando Cesar. Currículo e novas tecnologias no Ensino Fundamental. In: MORGADO, José Carlos; SANTOS, Lucíola Licínio de Castro Paixão;

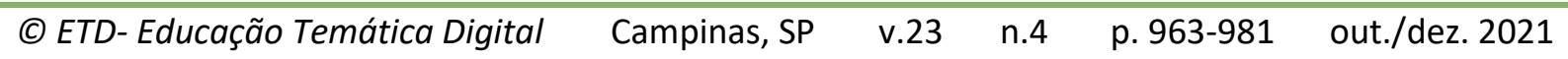


PARAYSO, Marlucy Alves (Org.). Estudos curriculares: um debate contemporâneo. Curitiba: CRV, 2013. p. 181-192.

NOAKSSON, Niklas; JACOBSSON, Kerstin. The production of ideas and expert knowledge in OECD. Stockholm: Score, 2003.

ORGANISATION FOR ECONOMIC CO-OPERATION AND DEVELOPMENT (OECD). Centre for Educational Research and Innovation (CERI). Education Committee. Draft programmes of work for 1981. Paris, 1980.

OECD. CERI. Education Committee. Draft programmes of work for 1982. Paris, 1981a.

OECD. CERI. Education Committee. Draft programmes of work for 1983. Paris, 1982a.

OECD. CERI. Education Committee. Draft programmes of work for 1983. Paris, 1985.

OECD. CERI. Education Committee. Education development in changing social, economic and technological conditions. Paris, 1981b.

OECD. CERI. Education Committee. OECD educational activities: comprehensive progress report for 1981. Paris, 1982b.

OECD. CERI. Education Committee. Resolution of the Council [C(70)134]. Paris, 1981c.

OECD. CERI. Seminar on computer sciences in secondary education: March $9^{\text {th }} / 14^{\text {th }}, 1970$ [Report]. Paris: OECD, 1971.

OECD. Convention on the Organisation for Economic Co-operation and Development. Paris, 14 dez. 1960.

OECD. Education at a Glance: OECD indicators. Paris, 10 set. 2019. Disponível em: http://www.oecd.org/education/education-at-a-glance/. Acesso em: 3 jun. 2020.

OECD. OECD at 50 and beyond. Disponível em: http://www.oecd.org/about/. Acesso em: 15 jan. 2017a.

OECD. Our mission. Disponível em: http://www.oecd.org/about/. Acesso em: 10 nov. 2016.

OECD. Who drives the OECD's work? Disponivel em:

http://www.oecd.org/about/whodoeswhat/. Acesso em: 14 jan. 2017b.

PAPADOPOULOS, George S. Education 1960-1990: the OECD perspective. Paris: OECD, 1994.

SOSSAI, Fernando Cesar. Ensino de História e "novas tecnologias educacionais". Joinville: Ed. da Univille, 2011.

SOSSAI, Fernando Cesar. Notas sobre o digital: historicidade e direcionamentos contemporâneos. Liinc em revista, v. 15, p. 53-69, 2019.

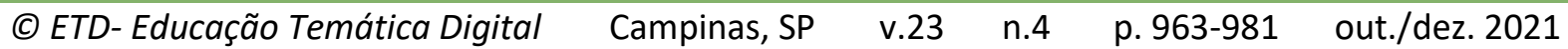


SOSSAI, Fernando Cesar; MENDES, Geovana M. L. Tempo tecnológico: uma análise de narrativas orais sobre o uso de tecnologias digitais em escolas públicas de Santa Catarina.

História oral, v. 19, p. 7-39, 2016.

SOSSAI, Fernando Cesar; MENDES, Geovana M. L.; PACHECO, José Augusto. Currículo e novas tecnologias em tempos de globalização. Perspectiva, v. 27, p. 19-46, 2010.

\section{Agradecimentos:}

Este artigo resulta de uma pesquisa científica que somente foi possível graças a duas fontes de financiamento, a saber: o Fundo de Apoio à Pesquisa da Universidade da Região de Joinville (FAP/Univille) e o Programa de Doutorado-sanduíche no Exterior da Coordenação de Aperfeiçoamento de Pessoal de Nível Superior (PDSE/CAPES). Expresso aqui meus sinceros agradecimentos à CAPES e à Univille pelos financiamentos recebidos.

Revisão gramatical realizada por: Marília Garcia Boldorini

E-mail: mariliaboldorini@gmail.com 